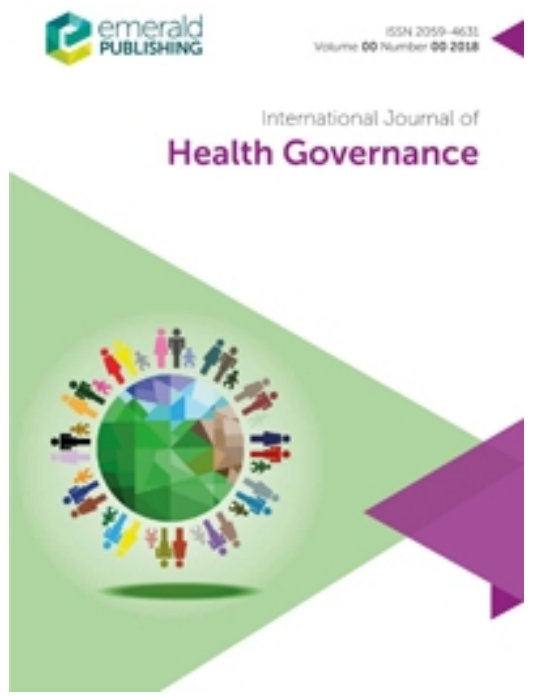

\title{
Behavioral Barriers of Tuberculosis Notification in Private Health Sector: Policy implication and Practice
}

\begin{tabular}{|r|l|}
\hline Journal: & International Journal of Health Governance \\
\hline Manuscript ID & ijhg-01-2020-0006.R1 \\
\hline Manuscript Type: & Original Article \\
\hline Keywords: & $\begin{array}{l}\text { Quantitative research < Research Methods, Behavioral, social or mental } \\
\text { health issues < Non-infectious conditions epidemiology, Organization < } \\
\text { Health Service Quality Assurance, Management of clinical performance } \\
\text { Health Service Quality Assurance, Healthcare commissioning < Health } \\
\text { Service Quality Assurance, Surveillance or screening < Public health }\end{array}$ \\
\hline \multicolumn{2}{|l}{} \\
\hline
\end{tabular}

\section{SCHOLARONE ${ }^{m}$ \\ Manuscripts}


Title: Behavioral Barriers of Tuberculosis Notification in Private Health Sector: Policy implication and Practice

\section{Short Title: Tuberculosis Notification in Private Health Sector}




\begin{abstract}
Purpose

Under-reporting of new tuberculosis (TB) cases is one of the main problems in TB control, particularly in countries with high incidence and dominating role of a private sector in TB cases diagnosing. The purpose of this paper was to explore behavioral determinants of under-reporting of new TB cases among private sector physicians in Iran.
\end{abstract}

\title{
Design/methodology/approach
}

We conducted a population-based, cross-sectional study of physicians working in private clinics. The data collection tool was designed using the theory of planned behavior. We used structural equation models with maximum likelihood estimation to examine attitude towards the notification behavior.

\section{Findings}

Of 519 physicians, 433 physicians completed the questionnaire. Attitude towards notification had the highest score (mean score $=87.65$; $\mathrm{sd}=6.79$; range: $0-100$ ). The effect of perceived behavioral controls on the notification behavior $((\hat{\beta})=0.13$; CI: .01-.25) was stronger than the total effect of attitude $((\hat{\beta})=0.06$; CI: .00-.12) and subjective norms $((\hat{\beta})=0.01 ; \mathrm{CI}:-.00-.03)$ on the behavior. However, attitude was the main predictor of intention and justified $46 \%$ of the intention variance. Intention had a significant effect on the behavior $((\hat{\beta})=0.09$; CI:.01- .16).

\section{Practical implications}

Considering stronger effect of perceived behavioral control on the behavior, interventions aiming at facilitating notification process would be more effective than those aiming at changing the attitude or enhancing intention among physicians.

\section{Originality/value}


To the best of our knowledge, no other study previously explored determinants of under-reporting from the behavioral and cognitive perspective. Specifically, we explored the role of the theory of planned behavior constructs in predicting intention to notify new TB cases.

Keywords: Case notification; Tuberculosis; Private sector; Public-private mix; Structural Equation Modeling; Theory of Planned Behavior

\section{Introduction}

The End Tuberculosis (TB) Strategy sets specific targets for 2030(Organization, 2016, Falzon et al., 2017):reduce TB incidence by $80 \%$, TB deaths by $90 \%$, and to eliminate catastrophic costs for TBaffected households(Organization, 2016). Nonetheless, of an estimated 10 million new TB cases that occurred in 2017, almost 3.6 million cases were under-reported(WHO, 2018). Following WHO, a 36\% gap between the estimated and reported number of new cases is due to under-reporting of detected cases, under-diagnosing, and uncertainty about the level of TB incidence(WHO, 2018).

The mandatory TB notification is an important policy under the End TB Strategy. However, cases detected and treated in the private sector do not necessarily get reported. This leads to underreporting, particularly in countries with high TB incidence and the dominating role of a private sector in TB cases diagnosing (Uplekar et al., 2016). Previous studies have shown that in countries with high TB incidence up to two-thirds of patients with early TB symptoms seek treatment in the private sector, primarily due to a higher perceived quality of care and easier access (Khan et al., 2012, Mills et al., 2002). At the same time, it was previously shown that up to $90 \%$ of patients in the private sector potentially receive TB treatment with inappropriate regimen (Khan et al., 2012). As a result, a higher rate of non-adherence to standard treatment protocols leads to a greater incidence of multidrug-resistant TB among private-sector patients(Uplekar et al., 2001), forming a vicious circle. 
New TB cases notification allows supporting private sector services with better practices and adherence to standards of a TB care which includes helping a patient to get the correct diagnosis, treatment, follow-up, and contact, as well as tracing, chemoprophylaxis and facilitates social support systems(Uplekar et al., 2001). However, despite several interventions and programs(Colvin et al., 2014, Zhang et al., 2011, Huaman et al., 2009, Ward et al., 2008), generally, less than a fifth of private-sector physicians feel obliged to report TB cases using their national routine reporting systems (Pethani et al., 2015a, Wells et al., 2011, Khan et al., 2012).

This could be due to the absence of appropriate legislation about the mandatory notification of new TB cases in the private sector and a lack of effective cooperation between public and private sectors (Wells et al., 2011, Nader and Askarian, 2009), as well as a lack of staff motivation and low awareness about the correct procedure of the new TB cases notification using the routine national system(Uplekar et al., 2001). Overall, the evidence on reasons for underreporting of new TB cases in the private sector remains scarce(Pethani et al., 2015b).

In 2018 , the total TB incidence in Iran was $11,000(8,500-14,000)$ people or $14(10-17)$ per 100,000 population, while the multidrug- and rifampicin-resistant TB incidence was 190 (100-310) people or 0.23 (0.12-0.38) per 100,000 population WHO report(WHO, 2016). In rural areas and county districts with a limited population, most TB cases are registered in the National TP Program (NTP) and receive standard treatment under supervision. However, in big cities, up to two-thirds of TB patients and those suspected to have TB prefer treatment in the private sector (Nader and Askarian, 2009, Ahmadi et al., 2013) (Pethani et al., 2015b).Although the private sector plays an important role in the TB program in Iran, its involvement and contribution to reporting smear-positive TB cases remain low(Pethani et al., 2015b) (WHO, 2006). The reasons and determinants behind the under-reporting of new TB cases in the Iranian private section remain unclear and require further investigation. 
This study aimed to examine cognitive determinants of under-reporting of new TB cases among privatesector physicians in Tehran, Iran. To the best of our knowledge, no other study had previously explored determinants of under-reporting from the behavioral and cognitive perspective. The reasons for choosing Tehran's primary private sector service providers as a study setting are three-fold: (1) the number of multidrug-resistant TB cases in Iran is rising (8cases in 2003 vs15cases in 2015 and about 190 cases in 2018(.23 per 100000)) in comparison, for example, to United Arabic Emirate and the UK, where less than 10 and 93 cases were reported in 2018 , respectively(WHO, 2019) ; (2) the Iranian private sector is the main provider of TB treatment in big Iranian cities(Ahmadi et al., 2015) (3);and Tehran, as the capital city, has the largest number of private service providers in the country, giving access to a diversity of service providers.

\section{Methods \\ Approach}

We explored the role of the theory of planned behavior (TPB) (Ajzen, 1991) in predicting intention to notify new TB cases. TPB was developed from the theory of reasoned action, and is more applicable when the probability of success and actual control over performance of a behavior are suboptimal. TPB's key contribution is the concept of perceived behavioral control, defined as an individual's perception of the ease or difficulty of performing the particular behavior (Ajzen, 1987). TPB hypothesized that the intention for notification is a function of three constructs (attitude, subjective norm, and perceived behavioral control) and the notification behavior comes after the intention, unless the perceived behavioral control hinders the actual behavior(Ajzen, 1991). Until now, various studies in health-related behavior fields have used this theory and have reported the efficacy of the model in explaining intention, perceived behavioral control and attitude across health-related behavior categories (Dumitrescu et al., 2011, Boudreau and Godin, 2007, Gantt, 2001, Armitage and Conner, 2001).

\section{Participants}


Of 23,307 general physicians in Tehran, registered as working more than three days per week in the private sector, 519 physicians were randomly selected to participate in the study. We deployed a stratified random sampling, based on the density of private clinics over the district areas. A list of participants containing names and working address was provided. Participants were approached in person in their clinics to fill out a questionnaire. One of the six trained interviewers was always available to clarify any questions about any item in question. Before the enrollment into the study, all participants gave verbal consent to participate. Non-consent was registered as a non-response.

\section{Measures}

To test hypothesis about determinants of notification behavior and related barriers among physicians working in the private sector, we adopted the basic model developed and tested by Ajzen (Ajzen, 2011, Ajzen, 1991). The study variables were defined using the TPB questionnaire(Francis et al., 2004, Ajzen, 2011)and results from a qualitative study(Ahmadi et al., 2013). 13 variables previously identified as notification barriers(Ahmadi et al., 2013) were used as indicators of three exogenous factors in the TPB model (i.e., factors that are not affected by other variables in the model are attitude (ATT), subjective norms (SN), and perceived behavioral control (PBC)). For every single indicator in each exogenous factor, two items were used according to the instruction of TPB questionnaire(Francis et al., 2004, Ahmadi et al., 2015).

The first sort of items was measured on a scale from 1 to 7 , while the second sort items ranged from -3 to +3. The multiplicative scores between each first sort item and its relevant second sort item were used to score each indicator for each exogenous factor in the model. Accordingly, there were three, three and seven multiplied scores for ATT, SN and PBC, respectively, ranging from -21 to +21 as detailed elsewhere(21). More detail in Appendix 1.Intention (INT) is the fourth component of TPB model and the first endogenous factor in this model. Intention indicates a person's readiness to perform a given behavior, and it is considered to be the immediate antecedent of behavior. It was measured(observed) 
based on the statement of doing notification in future cases by asking how many cases will be notified by the participant among the next 10 (ranged 0-10) new TB patients.

The outcome of the model, Behavior component, was dichotomous and measured as Yes or No, by asking participants whether they have notified at least one new diagnosed TB case during the last year. The reliability and validity of the questionnaire were obtained through two rounds of discussion among experts and a test-retest survey obtained from 20 potential participants (mean $\mathrm{ICC}=79.1 \pm 11.1$ ).

\section{Data analysis}

Questionnaires with more than half of questions left unanswered were considered as non-response and were excluded from the final analysis. For less complete cases, the mean imputation method was used. The score for every single indicator was calculated according to the scoring procedures described for each measure(Bledsoe, 2006) and reported. For estimation of the model's parameters, according to two-stage structural equation model(Mayhew et al., 2009, Bledsoe, 2006), at first, Confirmatory Factor Analysis (CFA) was used to score exogenous factors (ATT, SN, PBC). It yielded scores of participants' attitude, subjective norms and perceived behavioral controls, using loading scores of ATT, SN and PBC indicators, respectively. The structural equation modeling (SEM) analysis was then performed using the maximum likelihood estimation method.

\section{Ethical considerations}

Participation in the study was voluntary. Ethics approval was obtained from the ethical committee of Tehran University of Medical Sciences No: 89-04-102-12086

\section{Results}


Of 519 physicians, 433 physicians completed the questionnaire (response rate $=83.4 \%$ ), none of the variables had a missing ratio of more than 10\%. The mean (SD) age of participants was 47.6 (11. 4), of whom most were male (71.3\%). 30.3\% of respondents did not have any experience of working in the public sector. $62.6 \%$ of respondents were mainly working in their private clinics. Out of all respondents, $41.8 \%$ stated that they had suspected at least one new TB case within the last year. Only $43.4 \%$ stated that they had notified about at least one new TB case.

Participants believed that TB notification is good for community health (mean score 95.3; SD 14.6; range 0-100) while they did not assume that their colleagues performed $\mathrm{TB}$ notification (mean score 5.4; SD 05.5; range 0-100). They believed it increases their workload (mean score 88.4; SD 25.9; range 0-100). Attitude indicators had the highest scores among other model's factors(mean score87.6; SD 6.8; range 0-100). For SN, the mean score was 27.9; SD 20.9; range 0-100. For PBC, the mean score was 29.9; SD 16.7; range 0-100. Table1 shows scores for different indicators of each TPB's constructs.

In the SEM analysis (Figure 1), the numerical value of the total effect (direct and indirect) of attitude toward notification intention had the highest score and justified $46 \%$ of the intention variance. The effect of perceived behavioral controls on the notification behavior $((\hat{\beta})=0.13$; CI: $.01-.25)$, however, was stronger than the total effect of attitude $((\hat{\beta})=0.06 ; \mathrm{CI}: .00-.12)$ and subjective norms $((\hat{\beta})=0.01 ; \mathrm{CI}:-.00-.03)$. Intention had a significant effect on the behavior $((\hat{\beta}$ )$=0.09 ; \mathrm{CI}$ : .01- .16).. Subjective norms had a significant correlation with perceived behavioral controls (Pearson correlation $(\mathrm{r})=.252, \mathrm{p}=.01)$, but it had stronger correlation with attitude $(\mathrm{r}=.36$, $\mathrm{p}<.01)$. The correlation between attitude and perceived behavioral controls was significant as well $(\mathrm{r}=.19, \mathrm{p}=.03)$. Figure 1 and Table 2 show the result of SEM analysis results. The indices for the final model goodness of fit were acceptable. 


\section{Discussion:}

Despite a positive attitude and good intention toward the new TB cases notification behavior, the history of doing notification among the private sector physicians in this study was low. Less than half of physicians who had suspected a new TB case reported it. ATT and SN were important determinants of intention to notification while the effect of perceived behavioral control on intention was not significant. However, the direct effect of perceived behavioral control on actual behavior was notable and emphasized the importance of factors that imped turning intention to behavior in the private sector.

ATT was the main predictor of intention to the behavior (TB notification) in this study. In TPB model, there is no way of attitude to influence behavior but through intention. Therefore, the final prediction of behavior from attitude completely depends on the power of intention (as the mediator) to predict desired behavior(Fung et al., 2012). When the prediction of behavior through intention is low, the attitude power of prediction for behavior could not be high(Armitage and Conner, 2001). In private sector settings, interventions such as training and advertising in the form of influential sentences or providing graphs and statistics that demonstrate the benefits of notification could potentially strengthen physicians' behavioral beliefs(Blok et al., 2014), which is one of the two components that shape attitude (Ajzen, 2011). Also, financial benefits or career promotion and organizational credits can be considered as an intervention to strengthen the other component of attitude, the outcome of the evaluation(Arias, 2008). In general, for notification of new TB cases by physicians as occupational behavior, behavioral performance is mainly dependent on professional benefits or professional consequences that a person expects to follow after behaving or not behaving(Page et al., 2010, Raghuvanshi, 2002). SN construct is the second determinant of behavioral intention in the TPB 
model. The principal nature of $\mathrm{SN}$ is a variable called normative beliefs. Normative beliefs refer to a person's perception of the community's expectation (important people in the community or the prevailing wisdom the person is surrounded by) of whether the person would show the desired behavior or not(Ajzen, 2011). In our study, subjective norms have a decisive role in the prediction of the behavioral intention. Other studies decomposed subjective norms to find out effective interventions for behavioral change(Manning, 2009). One of the most noticeable interventions in this regard is the participation of opinion leaders (individuals who are important to the private sector physicians) in developing notification programs(Horne et al., 2018, Perry et al., 2007). Another way of strengthening normative beliefs in private sector physicians can be through public education about the importance of notification and its social benefits, since the demands of patients who refer to private sector physicians can influence the formation of physician's occupational normative beliefs (Gentina et al., 2017).

Siddaiah et al. (2019) showed that the proportion of patients with TB, who were notified by hospitals, was low. Findings of that study implied that due to the poor level of knowledge and awareness regarding TB notification, improving awareness among Indian healthcare providers about the requirement for TB notifications and their training was necessary for improving TB notification. At the same time, poor awareness and attitudes also have been mentioned in other studies as the barrier to TB notifications at the hospital to almost a quarter of those diagnosed(Lal et al., 2011, Nagaraja et al., 2014, Uplekar et al., 1998).

The main difference between the TPB model and its antecedent models is how behavioral controls are being perceived. The PBC is the third determinant of behavior that indicates one's beliefs about the availability of resources and opportunities to do a specific behavior(Ajzen, 2011). According to the TPB model, the main components of the PBC are beliefs in the 
existential nature of a specific agent (Control beliefs) and the individual's mindset about the amount of power of that agent (Perceived power) to facilitate or impede doing a desired behavior. It can affect behavior in two ways. The direct relation between PBC and behavior $(\mathrm{PBC} \rightarrow$ Behavior) is sometimes called Actual Behavioral Control(Gentina et al., 2017). The second pathway is between Perceived behavioral controls and behavior in the TPB, it is indirect through Intention (PBC $\rightarrow$ Intention $\rightarrow$ Behavior)(Ajzen, 2011). In our study, the direction of the first pathway (direct path) was incremental, meaning that the history of notification was more prevalent in those physicians who felt that they have enough power to do the notification. In other words, physicians stated fewer numbers of notified TB cases when they feel that the process of TB notification is too complicated. Unexpectedly, the indirect pathway (the path through the intention) between perceived behavioral control and the history of doing the behavior was reverse in direction, however, it was not significant.

The intention is the fourth determinants of behavior and the unique pathway of ATT and SN to influence behavior in TPB model (Ajzen, 2011, Bledsoe, 2006). However, intention alone is not enough for a specific behavior to be taken (Papies, 2017). Poor relationship between the intention and the behavior is a dilemma in behavioral studies and it was conceptualized in different ways (Papies, 2017). In TPB model, which we used in this study, the low level of perceived behavioral control can impede a positive intention to turn into a desired behavior(Cooke and Sheeran, 2004).Other justifications for the weak relationship between intention and behavior can be the existence of measurement errors in the implementation of the study and low variance of the variables (Cooke and Sheeran, 2004).To sum up, the interventions to bridge intention to behavior gaps are more likely to be effective in such situations when a low level of behavior is accompanied with high level of intention (Papies, 2017). 
We had some limitation in the study methodology and data gathering proccess.First, the measured behavior of notification was the past behavior. This limitation makes results susceptible to some systematic (social desirability bias) and accidental measurement errors, although it is commonly used in behavioral studies (Bou Malham and Saucier, 2016, Manning, 2009). Other limitation that might come out of the measuring past behaviour is recall bias. (i.e., physicians who had history of TB notification might have thought about barriers and facilitators, much more than those who did not. Second, we did not gather data on dual-practiced physicians or other type of private sectors that may potentially affect their answers. Although the study participants were approached in their individual private clinics, they might have worked in public sector and/or not-for-profit settings as well which might affect on thier actual measyres or they answers to study questions.

\section{Implications for policy, practice and future research:}

Policies, at all levels, should support facilitating TB notification process in the private settings which may have their specific barriers. We proposed a prospective through behavioral model toward TB notification that revealed special behavioral barriers. Although these barriers were described on an individual level, policies and programs at meso and macro levels can be considered as solution. Changing subjective norms about TB notification in private sector physicians from a "futile paperwork"to a"professional,productive activity", needs programs and policies that are accompanied by interactive communication with private physicians, and particularly, via opinion leaders. Furthermore, the process of TB notification can be "lightened up" by replacing long, complicated paper forms with online forms that require only a few clicks or taps. In doing so,policies should be written with an understanding of the contexts in which 
they will be implemented to allow for flexibility at the local level. To become effective and attractive, policies and programs should not create additional workloadin the way of establishing and maintaining TB notificationin the private sector.

Establishing support systems to overcome the challenges faced in TB notification process (e.g., extra workload), inevitably needs changing physicians behavior and practice. However,as our results that are in line with previous studies suggest, it is important to account for a patientphysicians relationship when considering new programmes and interventions that contain physicians behavior change. To promote behavioral changes, it is important to tailor interventionsto specific exisiting barriers. Moreover, it is crucial to have a clear understanding about how suggested interventions will change each component of the (notification)behavior.

We found a strong attitude and high level of intention toward TB notification in physicians who work in the private sector. Therefore, programs and interventions that aim to enhance attitude and its components (i.e., educational programs) may not be as effective as they used to be. New components of behavioral change to promote TB notification could be considered more often to interventional and comparative researches. We have proposed TPB model and its components as a well-known behavioral model. However, this model can be considered as an implication of behavioral models in dealing with disease surveillance system defects where their solutions directly depend on individual behaviors in different levels of health system.

\section{Conclusion}

Alongside the strong effect of attitude on intention, a good intention toward new cases TB notification among private sector physicians is likely to come from their peers and opinion leaders. However, physicians who have enough intention to do notification do not always successfully perform it. Most physicians do not get involved in the TB notification process 
because they do not feel enough control over the notification process. Conversely, our study findings suggest that the feeling of having enough power to do notification in some participants might come from the lower awareness about the notification barriers, especially when they have no prior experience of doing such notification. Considering stronger effect of perceived behavioral control on the behavior, it seems that interventions aiming at facilitating notification process would be more effective than those aiming at changing the attitude or enhancing intention in this population given the stronger effect of perceived behavioral control on the behavior.

\section{References:}

AHMADI, A., NEDJAT, S., GHOLAMI, J. \& MAJDZADEH, R. 2013. Disease surveillance and private sector in the metropolitans: a troublesome collaboration. Int J Prev Med, 4, 1036-44.

AHMADI, A., NEDJAT, S., GHOLAMI, J. \& MAJDZADEH, R. 2015. Tuberculosis notification by private sector'physicians in Tehran. International journal of preventive medicine, 6 .

AJZEN, I. 1987. Attitudes, traits, and actions: Dispositional prediction of behavior in personality and social psychology. Advances in experimental social psychology. Elsevier.

AJZEN, I. 1991. The theory of planned behavior. Organizational behavior and human decision processes, 50, 179-211.

AJZEN, I. 2011. The theory of planned behaviour: reactions and reflections. Taylor \& Francis.

ARIAS, K. M. 2008. Mandatory reporting and pay for performance: health care infections in the limelight. Aorn j, 87, 750-8.

ARMITAGE, C. J. \& CONNER, M. 2001. Efficacy of the theory of planned behaviour: A meta-analytic review. British journal of social psychology, 40, 471-499.

BLEDSOE, L. K. 2006. Smoking cessation: An application of theory of planned behavior to understanding progress through stages of change. Addictive behaviors, 31, 1271-1276.

BLOK, L., CRESWELL, J., STEVENS, R., BROUWER, M., RAMIS, O., WEIL, O., KLATSER, P., SAHU, S. \& BAKKER, M. I. 2014. A pragmatic approach to measuring, monitoring and evaluating interventions for improved tuberculosis case detection. Int Health, 6, 181-8.

BOU MALHAM, P. \& SAUCIER, G. 2016. The conceptual link between social desirability and cultural normativity. Int J Psychol, 51, 474-480.

BOUDREAU, F. \& GODIN, G. 2007. Using the Theory of Planned Behaviour to predict exercise intention in obese adults. Canadian Journal of Nursing Research Archive, 39.

COLVIN, C., MUGYABUSO, J., MUNUO, G., LYIMO, J., OREN, E., MKOMWA, Z., MAKAME, M., MWANGOMALE, A., MAHAMBA, V., MUELLER, L. \& RICHARDSON, D. 2014. Evaluation of community-based interventions to improve TB case detection in a rural district of Tanzania. Glob Health Sci Pract, 2, 219-25.

COOKE, R. \& SHEERAN, P. 2004. Moderation of cognition-intention and cognition-behaviour relations: A meta-analysis of properties of variables from the theory of planned behaviour. British Journal of Social Psychology, 43, 159-186. 
DUMITRESCU, A. L., WAGLE, M., DOGARU, B. C. \& MANOLESCU, B. 2011. Modeling the theory of planned behavior for intention to improve oral health behaviors: the impact of attitudes, knowledge, and current behavior. Journal of oral science, 53, 369-377.

FALZON, D., SCHUNEMANN, H. J., HARAUSZ, E., GONZáLEZ-ANGULO, L., LIENHARDT, C., JARAMILLO, E. \& WEYER, K. 2017. World Health Organization treatment guidelines for drug-resistant tuberculosis, 2016 update. European Respiratory Journal, 49.

FRANCIS, J., ECCLES, M. P., JOHNSTON, M., WALKER, A., GRIMSHAW, J. M., FOY, R., KANER, E. F., SMITH, L. \& BONETTI, D. 2004. Constructing questionnaires based on the theory of planned behaviour: A manual for health services researchers. Centre for Health Services Research, University of Newcastle upon Tyne.

FUNG, W. M., KOH, S. S. L. \& CHOW, Y. L. 2012. Attitudes and perceived barriers influencing incident reporting by nurses and their correlation with reported incidents: A systematic review. JBI Database of Systematic Reviews and Implementation Reports, 10, 1-65.

GANTT, C. J. 2001. The theory of planned behavior and postpartum smoking relapse. Journal of Nursing Scholarship, 33, 337-341.

GENTINA, E., KILIC, D. \& DANCOINE, P. F. 2017. Distinctive role of opinion leaders in the social networks of school adolescents: an investigation of e-cigarette use. Public Health, 144, 109-116.

HORNE, M., EMSLEY, R., WOODHAM, A., WEARDEN, A. \& SKELTON, D. A. 2018. Associations of intention to undertake physical activity among community dwelling British South Asian adults aged 60 years and over: a cross-sectional study. Public Health, 162, 1-8.

HUAMAN, M. A., ARAUJO-CASTILLO, R. V., SOTO, G., NEYRA, J. M., QUISPE, J. A., FERNANDEZ, M. F., MUNDACA, C. C. \& BLAZES, D. L. 2009. Impact of two interventions on timeliness and data quality of an electronic disease surveillance system in a resource limited setting (Peru): a prospective evaluation. BMC Med Inform Decis Mak, 9, 16.

KHAN, A. J., KHOWAJA, S., KHAN, F. S., QAZI, F., LOTIA, I., HABIB, A., MOHAMMED, S., KHAN, U., AMANULLAH, F., HUSSAIN, H., BECERRA, M. C., CRESWELL, J. \& KESHAVJEE, S. 2012. Engaging the private sector to increase tuberculosis case detection: an impact evaluation study. Lancet Infect Dis, 12, 608-16.

LAL, S., SAHU, S., WARES, F., LöNNROTH, K., CHAUHAN, L. \& UPLEKAR, M. 2011. Intensified scale-up of public-private mix: a systems approach to tuberculosis care and control in India. The International journal of tuberculosis and lung disease, 15, 97-104.

MANNING, M. 2009. The effects of subjective norms on behaviour in the theory of planned behaviour: a meta-analysis. Br J Soc Psychol, 48, 649-705.

MAYHEW, M. J., HUBBARD, S. M., FINELLI, C. J., HARDING, T. S. \& CARPENTER, D. D. 2009. Using structural equation modeling to validate the theory of planned behavior as a model for predicting student cheating. The Review of Higher Education, 32, 441-468.

MILLS, A., BRUGHA, R., HANSON, K. \& MCPAKE, B. 2002. What can be done about the private health sector in low-income countries? World Hosp Health Serv, 38, 24-30, 41-4.

NADER, F. \& ASKARIAN, M. 2009. How do Iranian physicians report notifiable diseases? The first report from Iran. American journal of infection control, 37, 500-504.

NAGARAJA, S., ACHANTA, S., KUMAR, A. \& SATYANARAYANA, S. 2014. Extending tuberculosis notification to the private sector in India: programmatic challenges? The International journal of tuberculosis and lung disease, 18, 1353-1356.

ORGANIZATION, W. H. 2016. WHO treatment guidelines for drug-resistant tuberculosis, World Health Organization.

PAGE, M. J., HARRISON, K. M., WEI, X. \& HALL, H. I. 2010. Federal funding for reporting cases of HIV infection in the United States, 2006. Public Health Rep, 125, 718-27. 
PAPIES, E. K. 2017. Situating interventions to bridge the intention-behaviour gap: A framework for recruiting nonconscious processes for behaviour change. Social and Personality Psychology Compass, 11, e12323.

PERRY, H. N., MCDONNELL, S. M., ALEMU, W., NSUBUGA, P., CHUNGONG, S., OTTEN, M. W., JR., LUSAMBA-DIKASSA, P. S. \& THACKER, S. B. 2007. Planning an integrated disease surveillance and response system: a matrix of skills and activities. $B M C$ Med, $5,24$.

PETHANI, A., ZAFAR, M., KHAN, A. A., RABBANI SANA, U., AHMED, S. \& FATMI, Z. 2015a. Engaging general practitioners in public-private mix tuberculosis DOTS program in an urban area in Pakistan: need for context-specific approach. Asia Pac J Public Health, 27, Np984-92.

PETHANI, A., ZAFAR, M., KHAN, A. A., RABBANI SANA, U., AHMED, S. \& FATMI, Z. 2015b. Engaging general practitioners in public-private mix tuberculosis DOTS program in an urban area in Pakistan: need for context-specific approach. Asia Pacific Journal of Public Health, 27, NP984NP992.

RAGHUVANSHI, V. S. 2002. Improvement in malaria services in an urban setting: role of staff motivation. Public Health, 116, 374-8.

UPLEKAR, M., ATRE, S., WELLS, W. A., WEIL, D., LOPEZ, R., MIGLIORI, G. B. \& RAVIGLIONE, M. 2016. Mandatory tuberculosis case notification in high tuberculosis-incidence countries: policy and practice. Eur Respir J, 48, 1571-1581.

UPLEKAR, M., JUVEKAR, S., MORANKAR, S., RANGAN, S. \& NUNN, P. 1998. Tuberculosis patients and practitioners in private clinics in India. The International Journal of Tuberculosis and Lung Disease, 2, 324-329.

UPLEKAR, M., PATHANIA, V. \& RAVIGLIONE, M. 2001. Private practitioners and public health: weak links in tuberculosis control. Lancet, 358, 912-6.

WARD, L. D., SPAIN, C. V., PERILLA, M. J., MORALES, K. H. \& LINKIN, D. R. 2008. Improving disease reporting by clinicians: the effect of an internet-based intervention. J Public Health Manag Pract, $14,56-61$.

WELLS, W. A., GE, C. F., PATEL, N., OH, T., GARDINER, E. \& KIMERLING, M. E. 2011. Size and usage patterns of private TB drug markets in the high burden countries. PLoS One, 6, e18964.

WHO 2006. Diagnostic and treatment delay in tuberculosis.

WHO 2016. Global tuberculosis report 2016.

WHO 2018. Global tuberculosis report, 2018: Tuberculosis Country Profiles. WHO/HTM/TB/2017.23 Geneva, Switzerland: WHO, 2018.Access in : http://www.who.int/tb/publications/global report/en/.

WHO 2019. Global tuberculosis report 2019. Geneva (Switzerland): World Health Organization; 2019.

ZHANG, T., GUO, L., ZHANG, S., LIU, W., CHEN, G., HUI, M., HE, G., VAN DER WERF, M. J. \& VAN DEN HOF, S. 2011. Improving detection and notification of tuberculosis cases in students in Shaanxi province, China: an intervention study. BMC Public Health, 11, 147. 
Table 1: standardized scores of the components of the theory of planned behavior

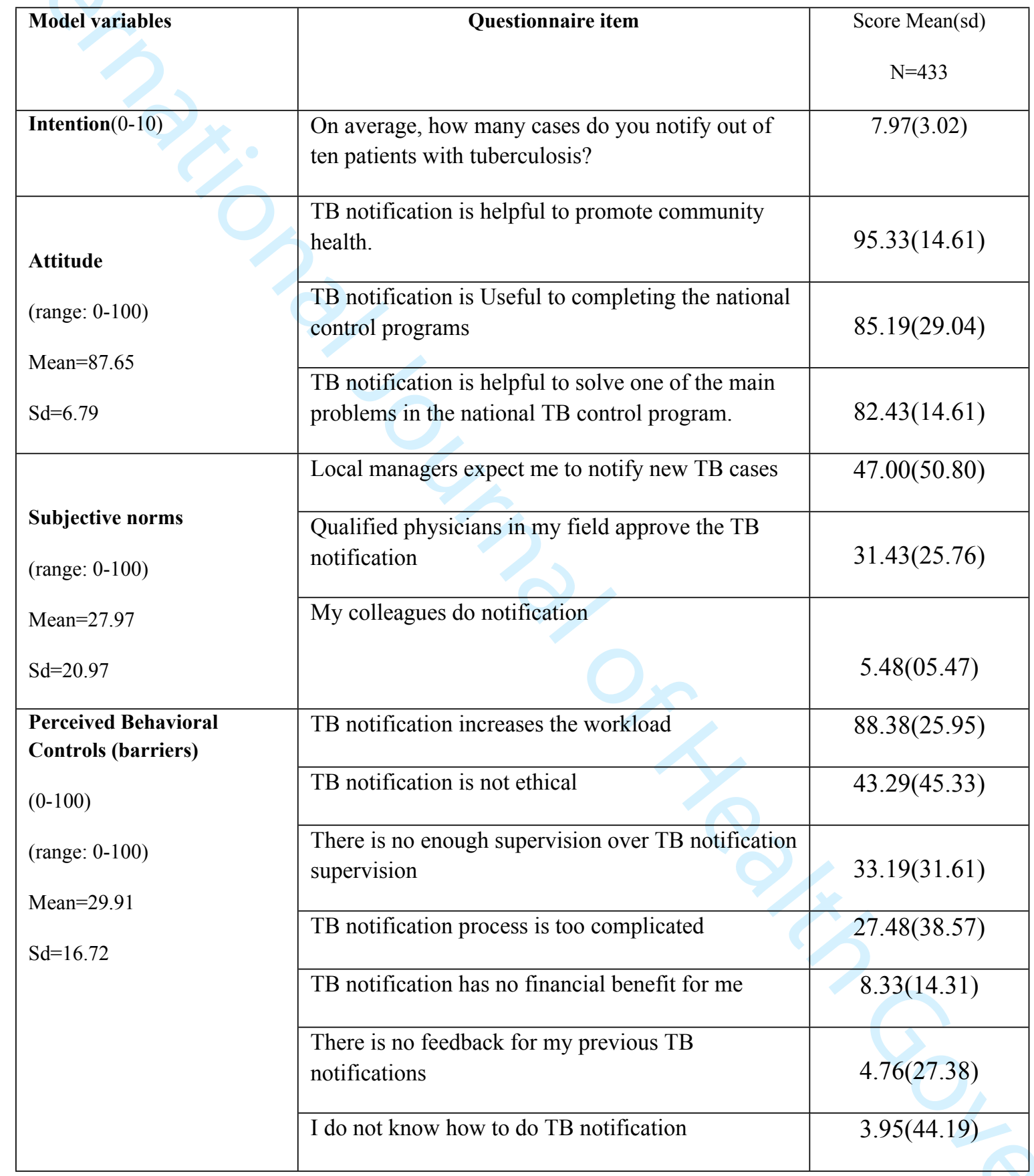

Note: N- sample size, SA - standard deviation, all items scores on 0-10 or 0-100 scale 
Table2: Unstandardized estimates (regression weight) of main parameters of the final model

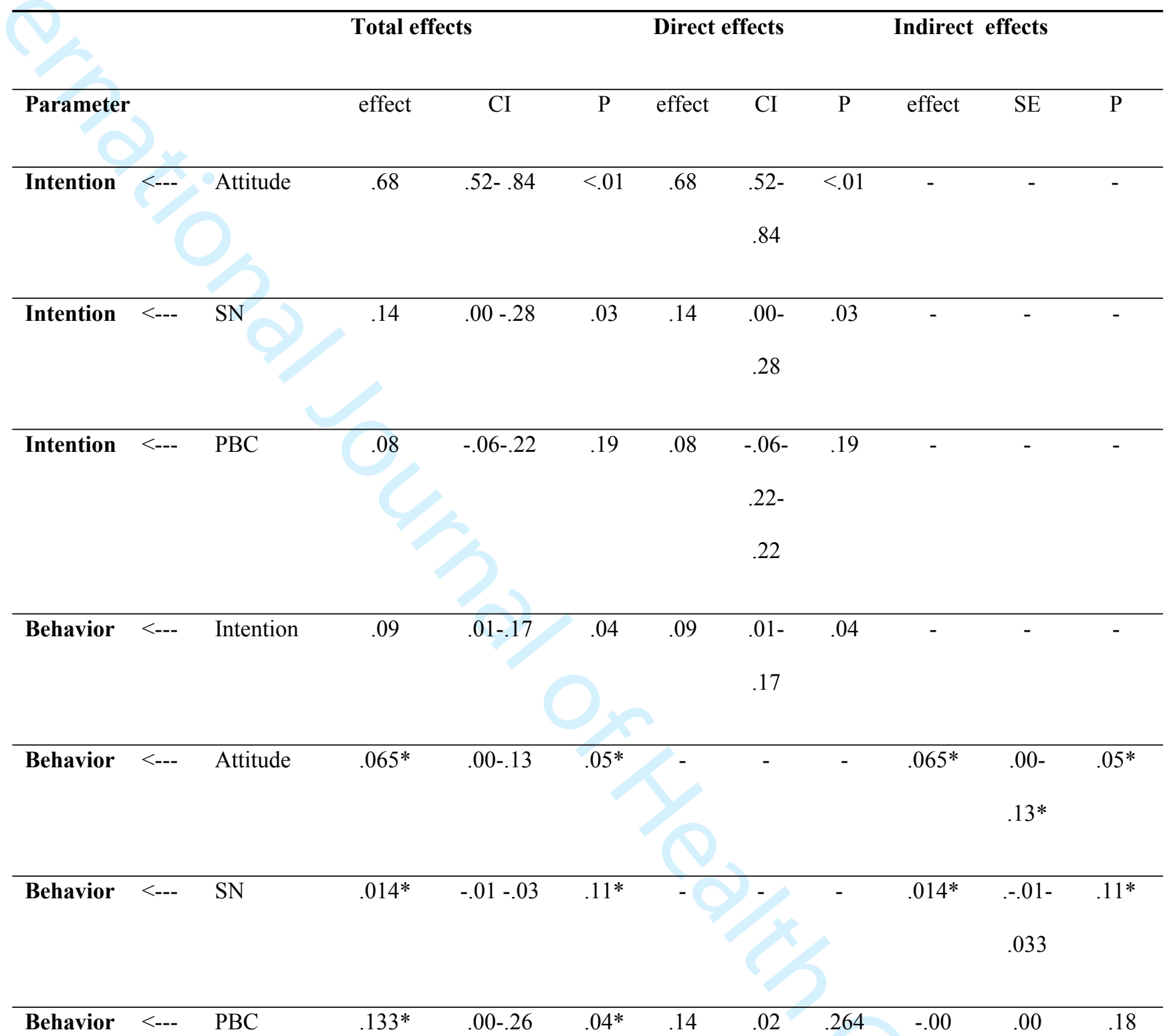

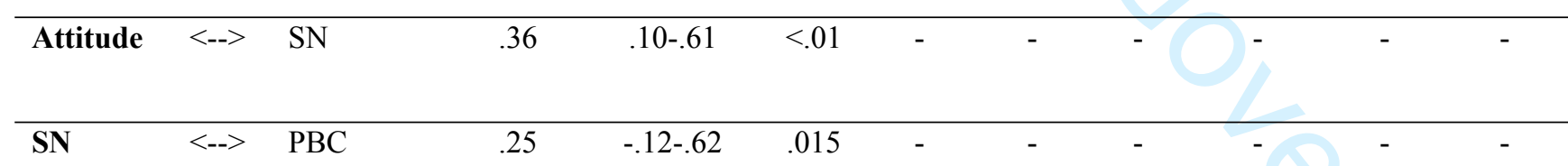

\begin{tabular}{l}
17 \\
4 \\
5 \\
6 \\
7 \\
8 \\
9 \\
0 \\
1 \\
2 \\
3 \\
4 \\
25 \\
6 \\
7 \\
8 \\
9 \\
30 \\
1 \\
32 \\
33 \\
4 \\
5 \\
36 \\
3 \\
38 \\
39 \\
40 \\
4 \\
43 \\
4 \\
45 \\
47 \\
48 \\
\hline
\end{tabular}
( 
